\title{
As Figurações de Lendas e Mitos Históricos na Construção da Cidade Tropical 1
}

\author{
Ana Luiza Carvalho da Rocha ${ }^{2}$
}

\section{Introdução}

Desde os tempos modernos a cidade é representada pela utopia de um espaço destinado a liberdade e a democracia. ${ }^{3}$ No entanto, paradoxalmente, a cidade urbanoindustrial como aglomeração densa de grupos humanos resultou nos mais diversos arranjos do espaço de vida coletiva. Através de estratégias finas e capilares de seu próprio percurso, a cidade moderna acabou produzindo o seu contrário e criando, em linhas gerais, processos de esquadrinhamento do espaço e das linhas de compartilhamento de seu território, das quais resultaram inúmeras práticas policialescas e redutoras por parte do poder público, responsável pela organização da vida social no meio urbano.

Para se compreender os dispositivos simbólicos que orientam tais paradoxos da fundação da cidade moderna, da qual somos herdeiros, há que se ressaltar que os dispositivos urbanos situam-se no centro do desenvolvimento técnico e material das sociedades humanas que se desenharam na superfície do globo terrestre. Das grandes civilizações agrícolas até os dias de hoje, tais dispositivos guardam o testemunho dos gestos e técnicas de sua comunidades de origem na forma como elas procederam (e procedem) seus ritos e mitos de possessão territorial.

Inspirando-se nos trabalhos de mitocrítica e mitanálise de G. Durand, pode-se salientar cinco estruturas funcionais que orientam a fundação da Cidade humana como obra da cultura, organizadas em duas grandes classes de imagens e símbolos sociais. ${ }^{4}$ Portanto, a cidade moderna, como obra da cultura, pode ser, assim, interpretada a partir das suas

\footnotetext{
${ }^{1}$ Palestra proferida no Seminário Cultura e Cidades, Prefeitura Municipal de Rio Grande/RS, Rio Grande, 1996.

${ }^{2}$ As idéias que desenvolvo aqui partem de algumas considerações contidas em minha tese de doutoramento, Le sanctuaire du désordre, ou l'art de savoir-vivre des douces barbares sous les Tristes Tropiques, defendida em 1994, na Universidade de Paris V, Sorbonne, sob a direção de Michel Maffesoli, onde aprofundo a forma como as utopias e os mitos do imaginário judeu-cristão do Conquistador europeu tecem os fios da estética da destruição no sul Brasil no que diz respeito a construção da "cidade de Deus" nos Trópicos.

${ }^{3}$ A propósito do discurso utópico da Modernidade que apresentam a Cidade como lugar da produção abstrata racional de conceitos, ver L. Marin, Jeux d'espace, Ed. de Minuit, Paris, 1973.
} 
"estruturas funcionais" de origem e das suas respectivas classes de imagens e símbolos arcaicos veiculados por seus mitos de fundação, os quais presidiriam o arranjo da vida coletiva no interior das distintas formas de aglomerações. ${ }^{5}$

De acordo com a arquetipologia de símbolos que a espécie humana empregou durante seu trajeto antropológico de apropriação do território geográfico - a passagem da economia das sociedades de coletores-caçadores, a domesticação de animais, o aparecimento da agricultura, a formação das classes sociais até o desenvolvimento do dispositivo urbano contemporâneo - pode-se subdividir as estruturas funcionais de uma cidade segundo 2 grandes classes de imagens. São elas as classes de imagens associadas aos gestos de conservação e de adaptação do homem ao seu ambiente cósmico e social.

Conforme tais classes de imagens, reconhece torna-se possível, portanto, o desvendamento de uma arquetipologia dos gestos e dos ritos de fundação da Cidade moderna, capazes de orientar a compreensão do surgimento das estruturas funcionais que assumem o dispositivo urbano contemporâneo no corpo dos fundamentos mitológicos que orientam a história das sociedades humanas.

Neste sentido, pode-se afirmar que toda a Cidade, mesmo no corpo de uma narrativa historiográfica, é guardiã de certa tradição que transparece no logos morfológico ao qual se filia, logos que pode é constantemente reinventado por seus herdeiros. Ou seja, da préhistória ao período industrial, as cadeias de evolução de seu dispositivo material fazem da Cidade um desafio ao antropólogo no sentido de desvendar o tipo de estruturas de mitos fundadores que lhe asseguram, ao mesmo tempo, a unidade e a estabilidade no tempo e que constituem-se numa síntese dinâmica do conjunto vivência de seus habitantes.

A primeira grande classe de imagens que aparece no corpo das formações do dispositivo urbano é aquela que tem por fundamento a ação/gesto humano de conservação, abarcando 2 estruturas funcionais:

- A estrutura predatória e suas funções de ataque e defesa.

A Cidade, sob o regime desta primeira classe de imagens, origina instituições e formas de trocas sociais baseadas numa ordem marcial, marcada pela tensão entre as "pulsões de fuga, de medo" de seus habitantes e "sob os imperativos de agressão" de povos vizinhos.

- A estrutura produtiva e suas funções de elaboração e de cultura dos alimentos

\footnotetext{
${ }^{4}$ Cf. o artigo de J-P. Sironneau, "Hermes ou la pensée du retour", publicado na obra La galaxie de 'imaginaire, dérive autour de l'oeuvre de Gilbert Durand, Paris, Berg International, 1980.

${ }^{5}$ A respeito, cito aqui o artigo de G. Durand, "La cité et les divisions du royaume", Eranos Jahrbuch, Zürich, 1976.
} 
A Cidade manifesta-se, aqui, como território capaz de manter a sobrevivência autônoma de seus habitantes a partir do seu esforço de dominar e domesticar os recursos da natureza através do desenvolvimento das técnicas, com o predomínio de arranjos sociais baseados numa ordem patrimonial, constituída pela dialética entre a pulsão consumidora e a ações produtivas de seus habitantes.

A segunda grande classe de imagens, refere-se as marcas de adaptação da espécie humana ao meio ambiente, onde pode se observar 3 tipos de estruturas funcionais daí decorrentes:

- estrutura mercantil e suas funções de trocas, de diálogo, de interação.

A Cidade guarda, neste caso, um sentido veicular, uma espécie de território de passagem, da qual origina-se uma ordem mercantil marcada, por um lado, por atos e pulsões de rapina e de roubo e, por outro, de troca e de reciprocidade entre seus habitantes.

\section{- Estrutura sacerdotal e suas funções de território santo, de "comunicação com o alem"}

A Cidade tem suas funções e instituições marcadas pela presença de símbolos veiculados por uma ordem sacerdotal (ou pontifical), conferida na dialética que estabelece entre as instituições que detém o poder mágico e o poder gnóstico.

- Estrutura imperial e suas funções de regulagem de regalias e privilégios que lhe são correlatas.

A Cidade e suas instituições com base em aparatos jurídico-legais tem a função precípua de estabelecer uma ordem hierárquica entre as 4 ordens anteriores, assegurando-lhes coerência e unidade, sendo, portanto, superior e colocando-se acima e além delas.

Neste contexto, a Cidade moderna, de acordo com os mitos e legendas históricas que veicula, pode ser contemplada como um território secularizado que se cria com o afastamento da ordem religiosa (sacerdotal) como instrumento de negociação entre os homens e a ascensão da figura do Déspota e do Jurista como figura capaz de promover o arranjo da vida social.

É, portanto, a estrutura funcional pautada na ordem imperial que funda a Cidade moderna, uma vez que, pela valência político-religiosa que acumula, o contrato social do qual origina-se o Estado nada mais faz que receber das ordens anteriores seu poder de legitimar e regular a vida coletiva.

Entretanto, na Modernidade, "a luta entre as figuras mitológicas do Sacerdote e do Imperador" representou, para o caso da Grande Tradição do Ocidente judeu-cristão, o seu desequilíbrio estrutural na forma como "os arranjos de vida coletiva oriundo da secularização 
do poder sacerdotal" em empreendimentos temporais cada vez mais transfigurou-se "na laicização do poder soberano nas democracias atuais". ${ }^{6}$

Conforme as duas grandes classes de imagens (conservação e adaptação), os agrupamentos de símbolos e mitos geradores, o trajeto antropológico que origina o nascimento da Cidade como forma de vida coletiva se configuraria segundo logos (logöi) morfológicos diferenciados, retratados nos rituais, nos acontecimentos e nas figuras que encarnam suas diferentes realidades sócio-históricas de pertencimento.

Em termos de estética urbana e memória coletiva, poder-se-ia dizer que as distintas formas que assumem os arranjos da vida coletiva citadina, nas mais diferentes civilizações, podem ser interpretadas segundo as diferentes modalidades de "realização empírica do logos morfológico que orientam suas fundações”, onde imagens isólogas (mythöi) de dispositivos urbanos podem corresponder a processos de individuações históricas (épöi) de agrupamentos humanos daí derivados". ${ }^{7}$

\section{A Cidade nos Trópicos}

Este ensaio, portanto, contempla algumas reflexões acerca do processo de instalação da civilização urbana na América a partir do logos morfológico no sentido de aprofundar seu pertencimento ao mito da ruína que encerra o drama da queda e redenção moral do conquistador europeu nos Trópicos.

Ironicamente, assim como aparecem no folclore e no imaginário popular colonial, são as figurações da "monstruosidade" e da "deformação" aquelas que mais perseguem os cientistas e pesquisadores quando, por força de seus princípios racionalistas e tecnocráticos, enfrentam o desafio de pensar as formas informes através das quais a Cidade nasce sob os trópicos. Em inúmeros casos, a Cidade tropical é apontada como teatro onde se espetaculariza o fracasso das fábulas progressistas européias projetadas nos arranjos da vida coletiva dos grandes centros urbanos das cidades latino-americanas.

Para enfrentar o desafio de se pensar as imagens da deformidade com as quais se investem as análises do fenômeno urbano no Brasil, há que se debruçar sobre os ritmos temporais que fundam a cidade tropical, ou seja, a memória coletiva que tais cidades são portadoras. Neste sentido, é de fundamental importância se ressaltar que a permanência da unidade simbólica da Cidade múltipla e plural no corpo das modernas sociedades urbanoindustriais da América Latina é aquela responsável pela presença insidiosa das imagens da

\footnotetext{
${ }^{6}$ Cf. J-P. Sironneau, op.cit., 94

${ }^{7}$ Cf. J-P. Sironneau, ibidem.
} 
"deformação" e da "monstruosidade" na compreensão da instalação da civilização urbana nos Trópicos.

Mais amplamente, apontaria para a presença do que denomino aqui o mito da ruína na forma como se apresenta a Cidade nos discursos das ciências sociais e históricas face à recorrência à figura do "homem da tradição" no corpo dos arranjos da vida social presentes às modernas sociedades urbano-industriais da América Latina.

Com isto quero dizer que, contra a unidade vazia de sujeitos sociais unificados pelo Cogito a partir do qual nascem as modernas cidades seculares, nos moldes do espaço homogêneo de tipo euclidiano, as cidades tropicais operam com a tensão entre o espírito iluministas de conquista, que orientou o pensamento ocidental do homem da civilização, nos Trópicos, e o seu duplo, a saber, a figura do homem da tradição, aquela que exacerbava os temores do Conquistador europeu em relação ao Novo Mundo.

Segundo aspecto importante a ser mencionado, decorrente do comentário anterior, é a referência recorrente as imagens de "monstruosidade "e deformação" nas representações do nascimento da América tropical, da qual nem mesmo Lévi-Strauss, em Tristes Tropiques, conseguiu escapar, decorrente da visão catastrofista que muitos intelectuais compartilham a respeito da lógica que rege o nascimento do fenômeno urbano no Brasil. Tal perspectiva é oriunda de uma tendência do pensamento social brasileiro em desqualificar uma certa "teologia temporal fundante" da colonização e povoamento da América barroca para conceber o fenômeno de instalação da civilização urbana. Transfigura-se, assim, as estruturas esquizomorfas compartilhadas pelo civilizador europeu, branco e cristão em abordagens analíticas sobre o fenômeno urbano, sem que se esclareça a filiação de tais imagens aos próprios mitos de fundação da América tropical.

Através da aplicação da lógica racional e de um tempo finalista, baseados na ordenação serial que orientou a disseminação do mito do Progresso no Novo Mundo, ignorase, nas análises científicas da gênese da Modernidade, em solo americano, e nas tentativas daí decorrentes de compreensão das patologias das transformações urbanas das "cidades tropicais", a herança temporal da tradição judeu-cristã que orienta a fundação da Cidade de Deus nos Trópicos. ${ }^{8}$ Uma arqueologia dos símbolos e dos mitos da fundação das cidades terrestres na América, que sempre gravitam: 'ora prósperas e pacíficas, ora afligidas por guerras e sedições". 9

\footnotetext{
${ }^{8}$ Ver, por xemplo, a obra de A.R. de Montoya, A conquista espiritual, POA/ Martins Livreiro, 1985.

${ }^{9}$ Interessante aqui reunir obras como as de Laura de Mello e Souza, O diabo e a Terra de Santa Cruz e de Sérgio Buarque de Hollanda, As visões do Paraíso com a obra de M. de Gandillac, Gêneses da Modernidade,
} 
Minha intenção é provocar uma re-orientação nas tradições de pensamento que buscam a compreensão da Cidade no Brasil tomando-se como ponto de reflexão as classes de imagens e as estruturas funcionais que fundam o "lugar da desordem" na configuração da estética urbana do país como parte do fenômeno histórico de fundação da América barroca. ${ }^{10}$ Ou seja, a civilização urbana nasce na América tropical marcada pela reconciliação das imagens dos anjos e dos demônios que habitavam o imaginário medieval ${ }^{11}$ com relação aos Trópicos no inconsciente luxuriante do Conquistador português.

Neste sentido, lá onde fracassa a "tirania do logos" intelectual para a compreensão dos arranjos de vida coletiva no meio urbano, nasce e adquire força a modéstia plural dos seus habitantes ao conceber a Cidade como território-mito, lugar de enraizamento de suas experiências afetivas e de seus símbolos sagrados.

Terceiro, destronando os deuses da religião tradicional e atuando com agentes das forças de secularização, a atuação dos tecnocratas acaba, finalmente, por perspectivar as análises do processo de urbanização na América tropical como o fracasso de um estilo cultural (a tecnópolis), valorado negativamente a partir da cronologia dos relógios e da fé produtivista.

É novamente a ubiqüidade do imaginário da América que pode responder pela presença anacrônica de um certo "tribalismo"12 na forma como se desenrola o nascimento da cidade secular na América, anacronismo que evocam intelectuais e burocratas quando acusam as populações urbanas do país de insubordinarem-se aos quadros vazios, regulares e monótonos do planejamento urbano e ao seu geometrismo mórbido.

Refiro-me aqui ao traço disruptivo que caracterizam as formas através das quais as populações urbanas do país ocupam os territórios da Cidade, transfigurando os seus quadros vazios em espaços afetuais, fecundando uma ambiência desértica em lugares de repouso e onde o clima de miséria e a atmosfera de violência desvelam de forma correlata, a insólita de "fome de viver" de seus habitantes.

RJ, Ed. 34, 1995, onde o autor analisa o compromisso da civilização "moderna", nascida na Europa ocidental sobre a base mediterrânea, com a fé cristã.

${ }^{10}$ Referência a obra de J. Teodoro, A América barroca, temas e variações. SP, EDUSP/Nova Fronteira, 1992.

${ }^{11}$ Penso aqui nos comentários de Todorov em sua obra, La conquête de l'Amérique la question de l'autre, Paris, Seuil, 1992.

${ }^{12}$ Muito embora pudesse aqui explorar a idéia de tribalismo desenvolvida por M. Mafessoli na sua obra Les temps des tribus, le déclin de l'individualismo dans les sociétés de masse, prefiro aqui fazer referência aos comentários de L. Mumford, A Cidade na História, SP, Martins Fontes, 1982, a respeito das raízes da cidade moderna que retrocedem a Idade da Pedra. Cf., igualmente, H. Cox, A cidade do homem, RJ, Paz e Terra, 1971. 
Finalmente, acredito que compreender o retorno constante do "homem da tradição" 13 no corpo de imagens de um visão progressista da vida coletiva nos grandes centros industriais do Brasil remete a um estudo bastante complexo acerca da forma como se perpetua a matéria nefasta dos Trópicos no interior do teatro da vida urbana do país e os vestígios do comportamento estético de um povo que habita um território destinado a ser o Paraíso perdido.

Proponho aqui que as imagens da deformação e do monstruoso com as quais operamos a compreensão das cidades tropicais seguem as marcas do nascimento da América barroca. ${ }^{14}$

A tese que defendo é que o logos morfológico da Cidade tropical e suas derivações históricas guardam em si uma filiação com mitos, deuses e rituais de fundação da Cidade de Deus gerado no corpo das tradições do Ocidente medieval judeu-cristão, abrigando um substrato religioso e místico que se polariza com o processo de secularização que vai se apossar da civilização ocidental na Modernidade.

O estudo do processo de instalação da civilização urbana na América Latina contempla as figurações ancestrais do Conquistador no imaginário da Europa ibérica, sendo, portanto, a expressão do arranjo estético de diferentes ritmos espaço-temporais advindos do processo de conquista, colonização, povoamento e descolonização do Novo Mundo.

\section{Paisagens noturnas sob Trópicos: a cidade colonial}

Para discorrer sobre o tema proponho-me aqui a restituir alguns pontos de inflexão por onde transitam as narrativas acerca do processo de ondulação temporal que preside a instalação da Civilização e do Progresso sob os Trópicos. ${ }^{15}$

Inicio esta parte de minha apresentação remetendo às imagens de terror e queda moral que acompanha a descida do conquistador português no Novo Mundo. ${ }^{16}$ Tais imagens do terror e da queda moral permitem importantes descobertas das figurações sociais da Cidade no imaginário latino-americano as quais associo três momentos que encerra o acontecimento

\footnotetext{
${ }^{13}$ A expressão "homem da tradição" é retirada da obra de G. Durand, Science de l'homme et Tradition, Paris, Berg. International, 1979, quando o autor refere-se a uma figura do homem que não se rende à uma razão histórica e as desfigurações do pensamento escolástico judeu-cristão.

${ }^{14}$ Um dos ângulos onde se pode observar estas imagens do monstruoso e da deformidade é na obra de R. Vainfas, O Trópico dos pecados, moral, sexualidade e inquisição no Brasil. RJ, Ed. Campus, 1988.

${ }^{15}$ Valho-me aqui dos capítulos de minha de tese de doutoramento Le sanctuaire du désordre, ou l'art de savoirvivre des tendres barbares sous les Tristes Tropiques, em particular aos capítulos da Parte I, "Uma geografia fantástica" e "A terra e seus filhos monstruosos".

${ }^{16}$ Ver a respeito, por exemplo, os inúmeros comentários de viajantes e missionários trazidos por G. Freire em sua obra clássica Casa Grande e Senzala, em especial no capítulo em que trata do tema da formação da família no Brasil.
} 
classes de imagens, mitos e ritos de fundação: cidade-colonial, cidade-imperial e cidadedemocrática.

Falo aqui de gestos e técnicas arcaicos que fundaram o corpo coletivo do Brasil em referência ao ato, que é ao mesmo tempo, de profanação e sacralização da Grande Mãe terra nos Trópicos realizado pelo homem europeu, branco e cristão (seja ele o Navegador, o Conquistador, o Missionário, o Aventureiro)e que, lentamente, irá transfigurar o território geográfico do Novo Mundo no centro de uma cosmologia medieval e de suas visões do paraíso.

Nos termos de uma mitocrítica, ou seja, das estruturas funcionais dos primeiros agrupamentos humanos construídos sob os Trópicos, constata-se que os primeiros núcleos de ocupação que o Herói civilizador constrói obedecem a classe de conservação. Assim, em sua função predatória, um dos primeiros atos do Conquistado foi a criação de fortificações e aldeamentos destinados a defesa e ataque com vistas a extração e rapina dos recursos naturais dos Trópicos tanto quanto dos corpos de seus nativos.

Muitas Cidades que hoje fazem da rota do turismo nacional (caso de Salvador, Olinda) cresceram sob os escombros desta ordem marcial de ocupação do território tropical onde estavam presentes tanto as pulsões de fuga e de medo do Civilizador quanto dos imperativos de agressão que este estabelecia com o meio cósmico e social da América.

O sedentarismo do Conquistador nos Trópicos nasce, portanto, sob o signo dos gestos e técnicas arcaicas do "homem da civilização" cuja presença no Novo Mundo evocava a luta entre anjos e demônios na construção de uma comunidade apostólica sob a linha do Equador. Tais vestígios de uma função predatória e de uma ordem marcial do "homem da civilização" na América portuguesa encontra-se hoje na forma como as elites do país que vivem nos centros urbanos densamente povoados criando defesas e muralhas contra a permanecia de mendigos e nômades urbanos, testemunhos sempre atuais da vida rústica, agrária, rural e patriarcal de outros tempos.

Mas o processo lento de descida do Conquistador português nos Trópicos não se encerra aí. Progressivamente sobrepõe-se a esta estrutura espaço-temporal outra classe de imagens e símbolos veiculadas ao Novo Mundo, de onde nascem novos núcleos humanos desempenhando outras estruturas funcionais que não a predatória dos ciclos econômicos extrativistas. Refiro-me aqui do surgimento do complexo "casa-grande e senzala" destinado ao cultivo e a técnica de produção de alimentos, e cuja ordem patrimonial se faz sentir ainda hoje como herança de nossas modernas cidades democráticas em suas derivações industriais e fabris. 
Nos quadros do mundo imaginal da sociedade brasileira muitos personagens das lendas históricas da ocupação territorial do Brasil - a figura arquetípica do Bandeirante - expressam este gesto de exploração e possessão da terra tropical do qual originaram-se muitas cidades, como por exemplo Porto Alegre, oriunda da sesmaria de Jerônimo de Ornelas,

Parte integrante da consolidação do período da conquista e do povoamento vivido pelo colonizador em seu processo ocupação territorial do Novo Mundo, a implantação da Civilização (e com ela as cidades industriais) nos Trópicos em suas feições predatórias e produtivas deve muito ao ritmo dos ciclos econômicos de exploração da terra e do metal no Novo Mundo, responsáveis pelo tecido acidental e descontínuo do tempo na formação das aglomerações urbanas no período colonial. ${ }^{17}$

Os primeiros povoamentos que despontam no período inicial da conquista compartilham, desde seus primórdios, da ambivalência das imagens apocalípticas que o herói civilizador nutria em relação aos Trópicos.

Aos olhos do homem da civilização, viajantes e missionários, as imagens da queda moral veiculadas pela vida na colônia falam, freqüentemente, do drama da morte do Conquistador europeu sob os Trópicos e de suas aspirações ascensionais de êxodo em direção à Terra prometida contidas na tradição ocidental cristã da época.

Não é por acaso que, no momento onde despontam as classes de imagens associadas ao gesto de conservação do Conquistador, a Cidade no Brasil nasce marcada pelo simbolismo da Espada e a figura do herói guerreiro tanto quanto pelo simbolismo da Cruz e a figura do santo missionário.

O nascimento das primeiras aglomerações no Brasil (vilas e vilarejos) acompanha, portanto, a polêmica ancestral, na memória coletiva de seu povo guiado pelo simbolismo nefasto que veicula a descida do herói civilizador no ventre da Grande-mãe Terra, dividindose em dois grandes momentos: o período da conquista e da colonização.

No período da conquista, a terra era tida pelo Conquistador branco como ventre devorador, arquétipo da mãe terrível, da mulher fatal e da feminilidade sedutora, pela força de sua matéria nefasta era capaz de "enfeitiçar", "seduzir" e "engolir" o herói civilizador, confundindo-o numa atmosfera de terror e pecado como "precipício profundo". ${ }^{18}$

Inicialmente apresentando-se como o ventre devorador de corpos e almas, arquétipo da feminilidade sedutora capaz de "enfeitiçar", "seduzir" e "exterminar" o herói conquistador,

\footnotetext{
${ }^{17}$ A leitura de M. I. Pereira de Queiroz, Cultura, Sociedade Rural e Sociedade Urbana no Brasil, ensaios, SP, EDUSP, 1978. é aqui no mínimo sugestiva.

${ }^{18}$ Ver a respeito F. Hartog (org) Le Nouveau Monde, Paris, Belles Lettres, La Roue des Livres, 1992.
} 
os ritos de possessão da terra tropical e o surgimentos dos primeiros vilarejos confundem-se com a atmosfera de terror e impureza de um território profano.

Conduzindo-se por atos belicosos e um nomadismo guerreiro, o europeu conquistador respondia a morte de corpos e almas brancas com a devastação das riquezas da terra tropical, o martírio e o suplício de seus habitantes, a criação de fortalezas e de reduções. ${ }^{19}$

O momento da colonização inaugura uma nova conduta ético-moral em relação a terra tropical. As imagens terrestres que associam o Novo Mundo a uma "garganta profunda" transfiguram-se lentamente, e a terra ressurge como ventre maternal e acolhedor, no período da colonização, símbolo de fecundidade e do repouso do Herói civilizador, de onde ele vai retirar sustento e alimento.

O surgimento do complexo imperial "casa-grande e senzala" apontado por Gilberto Freire, em sua obra clássica, e as pequenas aglomerações nascentes presas ao logos da vida colonial são tributários desta visão da terra tropical, lugar de delícias e de prazeres moralizados e domesticados, como pagamento e tributo à vertigem da sedução e da ruína do pecado dos primórdios da vida na América.

\section{A redenção moral do Conquistador: A cidade imperial}

Com o despontar do Brasil-imperial, e nos escombros de antigas fortificações, fazendas e estâncias, aldeamentos e pequenos vilarejos nascem os primeiros agrupamentos urbanos com funções mercantis e pontificais, com a Cidade assumindo lugar de destaque nas estruturas de trocas e de comunicação do corpo coletivo da sociedade brasileira, onde se faz presente as tensões entre as comunidades locais e a autoridade instauradora do Imperador.

A ordem mercantil e sacerdotal, neste período, avança sobre as duas ordens anteriores (predadora e produtora) porque são guiadas pela segunda classe de ações do Conquistador, a de adaptação aos Trópicos e suas respectivas estruturas funcionais.

Sob o ritmo da vida imperial, os símbolos e mitos que anunciam o nascimento da Cidade secular no Brasil retoma a tentativa de redenção moral do Conquistador nos Trópicos em seu desafio de construir a cidade terrestre no Novo Mundo assim como a arquetipologia de gestos e técnicas que configuram o nascimento de uma comunidade nos Trópicos dos Pecados.

\footnotetext{
${ }^{19}$ A propósito conferir por exemplo as narrativas contidas na obra de C. Bernard e S. Gruzinski, Le Nouveau Monde, de la découverte à la conquête e, igualmente, os relatos de $\mathrm{H}$. Staden, Duas viagens ao Brasil, SP, EDUSP/Itatiaia, 1988
} 
Neste contexto sócio-histórico, o nascimento de vilas e povoados se faz presente no folclore popular a partir de relatos que falam de serpentes encantadas, tesouros escondidos, mulheres enfeitiçadas e cataclismas que encarnam, nos mitos de fundação da Cidade, o simbolismo animal e lunar associado aos arquétipos da besta, da noite, do feminino nefasto e das águas.

No imaginário popular, o nascimento da Cidade aparece referido as catástrofes lunares que dão origem ao pelo homem brasileiro imerso, então, em paisagem noturnas de "noites sem fim", ameaçado por monstros e feras horripilantes (encarnando o seu passado colonial). Expressão estilística do tempo profano que anuncia o despontar da cidade secular nos Trópicos, os contos e lendas retratam o nascimento de vilas e cidades a partir da atmosfera primeira da luta do Herói civilizador na América, escondido em sombria e negras fortificações fincadas no ventre da terra tropical. Tal atmosfera de estetização do sofrimento e da agonia encontrava já sua expressão na densidade trágica da arte e arquitetura do barroco colonial no Brasil.

O que é marcante em tais lendas e contos que impregnam o quotidiano do Brasil colonial e imperial, é a presença da ordem sacerdotal sobreposta as funções mercantis da Cidade como aquela capaz de assegurar a perenidade de antigos povoados e vilarejos. Segundo tais relatos é no interior de uma paisagem nefasta de monstros, trovões, tremores de terra e tempestades, sob a evocação de figuras femininas sublimadas de Virgens Maria e Nossas Senhoras que ocorrem o nascimento das cidades no país.

Remontando-se aos relatos históricos da fundação da vida urbana no Brasil, ${ }^{20}$ não se pode deixar de notar que é ao redor de capelas e igrejas que seu corpo coletivo se forma. Capelas e igrejas que estão na origem da expansão da Cidade, na formação de seus bairros, anunciando um tempo feliz de paz e prosperidade para uma comunidade que apreende a passagem do tempo na forma como os antigos títulos e brasões patrimoniais associam-se aos bens e fortunas acumulados por comerciantes e aventureiros, sob a benção da fé e de figuras santas da igreja cristã.

Voltando-se a outra fonte de documentação, representada pela obra de inúmeros pintores estrangeiros, pode-se observar que a paisagem urbana da época é marcada pela presença de cidades portuárias, cuja marca confusional desvenda a herança de suas antigas ordens marcial e patrimonial: escravos e índios destribalizados, reunidos de forma

\footnotetext{
${ }^{20}$ Interessante aqui se voltar a obra de A. Cândido, Os parceiros do Rio Bonito, onde o autor comenta a centralidade do fenômeno do surgimento de cidades no interior do Brasil a construção de capelas e santuários.
} 
inconfundível num mesmo território, junto com aristocratas, nobres e comerciantes, numa convivialidade tecida por crenças e rituais religiosos comuns.

Ademais, adentrando-se nas narrativas de cronistas e viajantes ${ }^{21}$ sobre o quotidiano do Brasil dos primórdios do séc. XIX pode-se desvendar a Cidade como lugar onde o caráter disciplinar da figura do Imperador não se faz sentir. Populações citadinas ainda em gestação, submersas nas tensões entre o roubo e o contrabando e as instituições formais de troca e de intercâmbio, em cujas ruas comerciantes, financistas, aventureiros, barões e ouvidores conviviam entre um exército de criados, serviçais e escravos.

\section{O lugar da desordem: a cidade democrática}

Presa ao simbolismo do ciclo temporal sob os Trópicos, as cidades brasileira avançam, em sua feição democrática e republicana, sob o signo de uma ordem imperial. A República Velha nasce, assim, marcada pela ineficiência da função imperial, colocando-se como meta hierarquizar as ordens anteriores (marcial, patrimonial, mercantil e sacerdotal) através da coerência da irredutível diversidade que a Cidade abrigava desde seus primórdios como pequenos embriões de vida coletiva.

No esquema de G. Durand, a ordem imperial que rege a fundação da Cidade humana detém a função estrutural de simbolizar o conjunto humano total que abriga em seu interior. No Brasil, ela surge na ambiência psicosocial da descolonização da América para tomar corpo do processo de sua formação como Estado-nação moderno.

Tanto a Cidade democrática, durante os acontecimentos históricos da instauração da República (como é o caso do movimento abolicionista), desenvolve sua função imperial que ela é o palco da legitimação de novas regras de vida coletiva no Brasil ao apelar para vontade geral das maiorias e do consentimento e respeito à diferença como novo arranjos da vida social.

Sem destruir a legitimidade do poder do Sacerdote, que é absorvido pela figura do Jurista, e não mais a do Monarca, sem declinar em suas antigas funções estruturais predatórias, produtivas e mercantis, o processo de industrialização e urbanização nos tempos imemoriais da Cidade democrática, intensifica-se na busca do Progresso na Ordem.

Entre os deuses, mitos e figuras que incorporam a realidade sócio-histórica do logos morfológico imperial da Cidade democrática e sua busca de justiça, despontam Getúlio

\footnotetext{
${ }^{21}$ Um exemplo é a obra de A. Saint-Hilaire, op. cit.
} 
Vargas e Juscelino Kubistcheck e suas fabulas progressistas do verde-amarelismno e dos anos JK.

A arquitetura modernista de Brasília, por exemplo, mostra o quanto a sociedade urbana no Brasil pretende não ultrapassar a simplicidade rústica da antiga vida colonial com a criação dos grandes centros urbanos do país, ao projetar a importância de tomar "como lição" a arquitetura portuguesa colonial como ponto de inflexão de um movimento cultural que pretendia honrar, com a técnica, as luxuriantes e exuberantes formas e linhas da natureza tropical e de suas mulheres

Revelando a coerência irredutível da arquetipologia dos gestos e técnicas da fundação da Cidade humana, o que a moderna Cidade urbano-industrial tem de mais marcante em sua presença sócio-histórica nos Trópicos é que ela conserva num plano de igualdade as antigas estruturas funcionais das primeiras formações dos seus núcleos humanos não nos traçados das ruas e das praças, nas fachadas dos edifícios e casas, mas na estetização das formas coloniais e imperiais de se viver a cidade.

Ou seja, suas ordens marcial, patrimonial, mercantil e sacerdotal inspiram pluralmente as formas como seus habitantes apropriam-se do teatro da vida urbana nacional, sempre encompassados pelo sentimento de nostalgia do estado primordial do conquistador em sua busca da Terra prometida, e que foi projetado para o "novo mundo" nos tempos da descoberta da América.

A industrialização que, neste século, se fez acompanhar de um intenso processo de urbanização, tem como fonte de inspiração o forte sentimento nacional que nutria o "homem da civilização" do período da conquista no sentido de promover a redenção final da substancia edênica que encerrava as raízes históricas do território que abrigou seus antepassados. A construção de Brasília é um imponente símbolo do culto a tecnologia e aos saberes científicos como agente do universo democrático e da subjetividade moderna, não sem referir as mitologias que fundam a visão exuberante e luxuriante da terra tropical.

Território de projeção de fábulas progressistas e da fé produtivista onde despontam as imagens do avanço técnico e da industrialização, a Cidade-democrática no Brasil, pelo traço heteróclito dos desdobramentos de seu crescimento informal, desigual e descontrolado, irá abrigar um ecletismo descrito por muitos como o mito da "ruína" e do "atraso".

O espírito de tolerância dos habitantes dos grandes centros industriais em relação as suas experiências acumuladas com o passado fazem com que acusemos o processo de urbanização no país de estar a mercê de uma espécie de anti-história com a qual o tecnocrata deve se confrontar em sua tentativa de ordenação do caos urbano. 
Afinal o que poderia perguntar: - de onde vem este mito da ruína e do fracasso que as pesquisas tem tentado desvendar na análise da paisagem urbana do Brasil? Creio que parte da resposta esta contida no "espírito de tempo" que reina na Cidade democrática dos Trópicos. Em sua expressão estética da desordem, a cidade latino-americana é democrática por excelência ao revelar-se como território onde uma comunidade exercita a função equilibrante das antigas estruturas espaços-temporais herdadas com o passado, beneficiandose do "direito a diferença" dos estilos de vida de seus habitantes.

Anti-totalitária, a Cidade tropical em sua feição de "formas informes" permite a manifestação da diversidade de sentidos na forma como os grupos humanos apropriam-se de seus espaços, denunciando o relativismo cínico de uma cultura democrática homogeneizadora que prega a "autonomia" dos grupos urbanos sem referência aos territórios em que se enraízam.

A estética da desordem e da fome que preside os arranjos da vida social nos grandes centros urbanos do país embora sendo freqüentemente associada a uma espécie de resíduo subterrâneo do "pensamento selvagem" do povo que nela habita, mostra, bem ao contrário, os desvios que toma o processo de ocidentalização dos Trópicos ao denunciar seus mitos faustianos de riqueza e prosperidade..

As "deformidades" das favelas, da criminalidade, dos mendigos, dos cortiços, dos acidentes de automóveis, dos roubos e assassinatos, da violência policial, da corrupção dos "colarinhos brancos" assumem a perspectiva das distorções do "racionalismo triunfante e plano" contido na idolatria do Progresso e em sua confiança desmesurada dos arranjos lógicoformais da era democrática.

\section{Conclusões}

A polimorfia confusional que preside a estética urbana das cidades do Brasil faz parte, portanto, do processo de modelagem do ritmo das vibrações temporais que funda o corpo coletivo na América Tropical, registrando a memória coletiva de seu povo.

Advogo, portanto, que a análise do fenômeno urbano no Brasil, por parte de historiadores e cientistas sociais, não pode ignorar o processo de consolidação temporal que acompanha a formação de seu corpo coletivo, de colônia à sua feição atual de Estado-nação, sob o risco de ignorar o logos morfológico que preside a exploração, conquista e povoamento das "terras tropicais" como parte da herança de seus modernos centros industriais.

Observando-se com acuidade os mitos de fundação de inúmeras cidades brasileiras como São Paulo, Rio de Janeiro ou Porto Alegre pode-se perceber que em suas origens tais 
centros evocam, de muitas formas, as ondulações do tempo vividas pela sociedade brasileira desde seus tempos primordiais sendo assimiladas a dramática das guerras e lutas de conquista dos Trópicos pelo colonizador português.

Atentos a tais acontecimentos, pode-se perceber a ondulação temporal vivida pela sociedade brasileira desde seus primórdios, incidindo num logos morfológico que dá sentido à Cidade na memória coletiva local. Da mesma forma, a eles correspondem mitos e ritos de fundação de distintos dispositivos urbanos no país, e cujos símbolos e imagens que veiculam revela-se a existência de uma cosmologia singular que explica a instalação da civilização urbana no Brasil .

\section{Referencias}

BERNARD, C. e Gruzinski, S. "Le Nouveau Monde, de la découverte à la conquête". Paris, Fayard, 1991.

CÂNDIDO, A. "Os parceiros do Rio Bonito". SP, Duas Cidades, 1987. COX, H. "A cidade do homem". RJ, Paz e Terra, 1971.

DURAND, G. "La cité et les divisions du royaume", in: Eranos Jahrbuch, Zürich, 1976.

DURAND,G. "Science de l'homme et Tradition". Paris, Berg. International, 1979. FREIRE, G. "Casa Grande e Senzala, a formação da família brasileira sob o regime de economia patriarcal". Rio de Janeiro, José Olimpo, 1958.

GANDILLAC, M. de "Gêneses da Modernidade". Rio de Janeiro, Ed. 34, 1995

HARTOG, F (org) "Le Nouveau Monde". Paris, Belles Lettres, La Roue des Livres, 1992.

HOLLANDA, S.B. de. "Visão do Paraíso, os motivos edênicos no descobrimento e colonização do Brasil". São Paulo, Cia das Letras, 1969.

MAFESSOLI, M Le temps des tribus, le déclin de líndividualisme dans les sociétés de masse. Paris, Méridiens Klinscksieck, 1988.

MARIN, L. Jeux d'espace. Paris, Ed. de Minuit, 1973.

MELLO e SOUZA, L. de O diabo e a Terra de Santa Cruz. São Paulo, Cia das Letras, 1994.

MONTOYA, A.R. A conquista espiritual. POA, Martins Livreiro, 1985.

MUMFORD, L. Cidade na História. SP, Martins Fontes, 1979.

PEREIRA de QUEIRÓZ, M. I. Cultura, Sociedade Rural e Sociedades Urbana no Brasil, ensaios. SP, EDUSP, 1978.

ROCHA, A. L. Carvalho da Le sanctuaire du désordre, ou l'art de savoir-vivre des douces barbares sous les Tristes Tropiques. Tese de doutoramento defendida na Universidade de Paris V, Sorbonne, 1994, sob a direção de Michel Maffesoli.

SIRONNEAU, J.P. "Hermes ou la pensée du retour", in: La galaxie de l'imaginaire, dérive autour de l'oeuvre de Gilbert Durand, Paris, Berg International, 1980.

SAINT-HILAIRE, A. Duas Viagens ao Rio Grande do Sul. Belo Horizonte, Itatiaia, 1978. STADEN. H. Duas viagens ao Brasil. SP, EDUSP/Itatiaia, 1988.

TEODORO, J. A América barroca, temas e variações. SP, EDUSP/Nova Fronteira, 1992. TODOROV, T. La conquête de l'Amérique, la question de l'autre. Paris, Seuil, 1992.

VAINFAS, R. O Trópico dos Pecados. RJ, Ed. Campus, 1989. 